\title{
Are gold markets weak form efficient? Evidence from China, India and Russia
}

Bisharat Chang ${ }^{1 *}$, Pervaiz Ahmed ${ }^{1}$, Niaz Ghumro ${ }^{1}$, Mujeeb-U-Rehman Bhayo ${ }^{1}$

\begin{abstract}
:
The main purpose of this study is to determine the weak form efficiency of the emerging gold markets such as China, India and Russia with the special focus on testing random walks (RWS) and martingale difference sequence (MDS) hypotheses during different periods of time. This study uses bias free statistical techniques such as runs test, parametric variance ratio tests and recent modified non-parametric variance ratio tests based on ranks and signs by using daily spot gold prices from January 12, 1993 to October 28, 2016. Findings of the study suggest that Russian gold market is weak form efficient throughout the period whereas other two markets are found weak form efficient during second sub period only that is, January 2000 to December 2005.
\end{abstract}

Keywords: variance ratios, Ranks and signs, emerging gold markets, Random walks, Martingale.

JEL classification: G1, G14, G17.

\section{Introduction}

Gold is considered as one of the most important and precious metals (Blose, 1996; Blose and Shieh, 1995; Dubey et al., 2003). It serves the different purposes for agents in the market. First, it is used as raw material for producing technological and electronic goods (Rockerbie, 1999; Solt and Swanson, 1981). Second, it is used as an ornaments such as jewelry (Batchelor and Gulley, 1995; Baur and McDermott, 2010). Third, it is used as security for hedging risk and portfolio diversification (Davidson et al., 2003; Wang et al., 2011). Fourth, it is used as store of value and safe haven for investors and central bankers (Baur and Lucey, 2010; Baur and McDermott, 2010). Fifth, it is used as currency such as coins and medium of exchange (Chang et al., 2013; Sjaastad, 2008). Keeping in view these facts the study of gold price behavior has been a topic of interest for researchers. Because of various uses of gold (e.g technology, monetary, jewelry, investment and central banking) understanding the behavior of gold returns in weak form efficient market context is very important for researchers, regulators, policy makers and investors. Belaire-Franch and Opong (2010) mention that researchers usually try to understand how the security prices behave over time, whereas the practitioners and investors (such as speculators, hedgers and arbitrageurs) try to exploit

* Corresponding Author: bisharat.phdmgt17@iba-suk.edu.pk

${ }^{1}$ Department of Business Administration, Sukkur IBA University

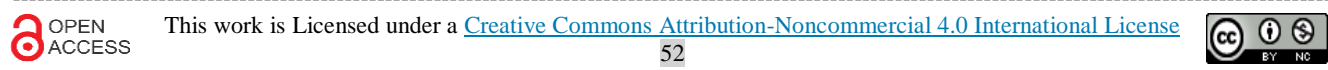


the behavior of market inefficiencies. On the other hand, regulators and policy makers try to increase the pricing efficiency of financial assets, and in order to increase this pricing efficiency they increase the speed of information flow in gold markets. The behavior of gold price returns is, therefore, very important to understand for participants and key actors in financial markets.

A vast literature is available that has focused on gold prices and markets and those various studies have analyzed the gold in different strands. First strand of literature has determined the cointegration and/or causality relationship between macroeconomic variables and gold prices/markets by using different ARCH models (Sjaastad and Scacciavillani, 1996; Tully and Lucey, 2007; Zhang and Wei, 2010). Second strand of literature has examined the spillovers, linkages, interdependencies and efficiencies amongst the gold markets (such as US, UK and Japan) and between gold and other markets (such as other precious metals, bonds and stocks) (Caminschi and Heaney, 2014; Chang et al., 2013; Ewing and Malik, 2013; Xu and Fung, 2005). Third strand of literature has examined the role of gold as security for risk and portfolio diversification, derivative and hedging instrument, store of value and safe haven (Baur and Lucey, 2010; Baur and McDermott, 2010; Davidson et al., 2003; Wang et al., 2011). The final strand of literature, which is directly related to the purpose of this study, has analyzed the predictability of gold market returns (Baur, 2013; Blose and Gondhalekar, 2013; Mills, 2004; Monroe and Cohn, 1986; Pierdzioch et al., 2014; Tschoegl, 1980; Wang et al., 2011; Yu and Shih, 2011).

Literature available on the weak form efficiency of gold markets is, however, not free from limitation. Results of most of those studies are mixed even within the same study, such as some of the studies provide evidence for the existence of weak form efficiency in gold markets (Beckers, 1984; Ho, 1985; Pierdzioch et al., 2014; Tschoegl, 1978), whereas other studies indicate that the gold markets are not weak form efficient (Basu and Clouse, 1993; Baur, 2013; Blose and Gondhalekar, 2013; Narayan et al., 2010; Shafiee and Topal, 2010) whilst other studies show the mixed results (Parisi et al., 2008; Wang et al., 2011).

Possible reasons for inconsistent results about gold markets efficiencies are that most of the previous studies have used the techniques such as serial correlation tests, autoregressive and Autoregressive integrated moving average (ARIMA) models which may not be successful due to presence of different econometric issues in the data such as heteroscedasticity and non-normality. Moreover, Lim and Brooks (2011) suggest that there is new paradigm which plays its role in the efficient markets, that is, adaptive market hypothesis (AMH). This new hypothesis states that efficient market hypothesis and behavioral finance may logically and consistently be persistent with each other and market efficiency does not remain fixed over time but changes with the passage of time (Lim and Brooks, 2011).

Keeping in view the limitations in the existing literature, this study extends previous literature in two directions. First, it uses robust statistical techniques such as variance ratio tests proposed by Lo and MacKinlay (1989) and Wright (2000)Lim and Brooks, 2011 for testing strict random walks (RWS) and relaxed martingale difference sequence (MDS) hypothesis. Second, this study divides data into different periods to

Sukkur IBA Journal of Management and Business - SIJMB | Volume 5 No. 1 January - June 2018 @ Sukkur IBA University 
determine whether the efficiencies of the gold markets change with the passage of time. Rest of the paper is organized as follows. Section 2 describes data sample, descriptive statistics of the data, runs test, and various parametric and non-parametric variance ratio tests; section 3 provides discussion and analysis of results and section 4 concludes the paper.

\section{Data and Methodology \\ 2.1. Data and Sample}

Daily data for spot gold prices is taken from world gold council (WGC) website for Russia, India, and China, that covers the period from January 12, 1993 to October 28, 2016. This study focuses on these three emerging countries only out of four BRIC countries since the data for Brazil is not available at WGC website. Returns are then calculated by taking the log difference of daily spot gold prices:

$$
r_{t}=\ln \left(\frac{p_{t}}{p_{t-1}}\right)
$$

Where $\ln$ is the natural logarithm and $p_{t}$ and $p_{t-1}$ indicate daily spot gold prices at time $t$ and $t-1$ respectively.

Following Mobarek and Fiorante (2014), who tested the weak form efficiency of BRIC (Brazil, Russia, India and China) equity markets, this study further extends analysis by dividing the data into three sub groups ${ }^{2}$. Like equity markets as suggested by Mobarek and Fiorante (2014), there is possibility that the changes in market environments as well as changes in reasonable structural breaks may have changed the market efficiency of gold markets as well. Data for first subgroup, which covers period from January 1993 to December 1999, is mainly due to the Asian crisis started in 1997 which directly affected the Asian countries. Russia also faced serious crisis in 1998 caused by Asian crisis. Second subgroup, which covers period from January 2000 to December 2005, focuses "dotcom bubble," which had also great impact on major industrialized countries. Last period that is from, January 2006 to October 2016 covers 2008 global financial crises.

Table 1 provides descriptive statistics of gold returns for whole sample as well as three subsamples. On average mean returns and standard deviation for Russian gold market are higher than Indian and Chinese gold markets specially for whole sample as well as for sub_period 1 (1993-1999) and sub_period 3 (2006-2016), High returns and standard deviation for Russia indicate that gold market in Russia is relatively riskier. Hence returns are higher for Russia as well to compensate the extra risk. Minimum and

\footnotetext{
${ }^{2}$ Mobarek and Fiorante (2014) tested weak form efficiency of BRIC equity markets by covering the period from September 1995 to March 2010. They further divided the data into three sub periods i.e sub period 1: 1995:09-1999:12, sub period 2: 2000:01-2005:12, sub period 3:2006:01-2010:03, in order to confirm whether efficiency of equity markets may have evolved over time.
} 
maximum values also indicate the higher volatility for Russia that is around $47 \%$ to $36 \%$ for whole sample period as well as for first sub_sample period (1993-1999). However, for second sub_sample period all three markets become equally volatile having maximum and minimum values around $6.5 \%$ to $-5.4 \%$ respectively. Hence it can be concluded that in period two all three markets provide almost equal mean returns and are equally risky as well. Jarque Berra statistics indicate that returns are not normally distributed for all countries for whole sample as well as for all sub samples, as the null hypothesis of normal distribution is rejected in all cases.

Table 01: Descriptive Statistics of daily gold returns

\begin{tabular}{llllll}
\hline Market & Mean & Max & Min & $\begin{array}{l}\text { Std. JarqueBera } \\
\text { Dev. }\end{array}$ & $\begin{array}{l}\text { No of } \\
\text { Obs. }\end{array}$ \\
\hline
\end{tabular}

Full Period : 1993:01-2016:10

\begin{tabular}{lllllll} 
China & 0.001 & 0.408 & -0.096 & 0.01 & $16198659 * * *$ & 6209 \\
India & 0.001 & 0.071 & -0.094 & 0.01 & $10871.7 * * *$ & 6209 \\
Russia & 0.002 & 0.465 & -0.364 & 0.03 & $5804470 * * *$ & 6209 \\
\hline
\end{tabular}

Sub period 1: 1993:01-1999:12

\begin{tabular}{|c|c|c|c|c|c|c|}
\hline China & 0.001 & 0.408 & -0.054 & 0.01 & $2743566 * * *$ & 1825 \\
\hline India & 0.001 & 0.059 & -0.036 & 0.01 & $1963.838 * * *$ & 1825 \\
\hline Russia & 0.002 & 0.465 & -0.364 & 0.02 & $498324.3 * * *$ & 1825 \\
\hline
\end{tabular}

Sub period 2: 2000:01-2005:12

\begin{tabular}{lllllll} 
China & 0.001 & 0.064 & -0.054 & 0.01 & $2532.227 * * *$ & 1565 \\
India & 0.001 & 0.065 & -0.053 & 0.01 & $2622.658 * * *$ & 1565 \\
Russia & 0.001 & 0.065 & -0.053 & 0.01 & $2082.024 * * *$ & 1565 \\
\hline
\end{tabular}

Sub period 3: 2006:01-2016:10

\begin{tabular}{lllllll} 
China & 0.001 & 0.067 & -0.096 & 0.01 & $2583.76 * * *$ & 2825 \\
India & 0.001 & 0.071 & -0.094 & 0.01 & $2479.221 * * *$ & 2825 \\
Russia & 0.002 & 0.137 & -0.160 & 0.02 & $17518.16 * * *$ & 2825 \\
\hline
\end{tabular}

*** indicate that the null hypothesis of normality is rejected for all countries and all sample periods studied at $1 \%$ significance level.

\subsection{Methodology}

This study focuses on runs test as well as parametric variance ratio tests proposed by Lo and MacKinlay (1988), and Lo and MacKinlay (1989); and modified non parametric variance ratio tests using ranks and signs proposed by Wright (2000) for testing the strict random walks (RWS) and relaxed martingales difference sequence (MDS) hypothesis of weak form market efficiency. Different variance ratio tests have been 
proved as robust tests since they provide more accurate results for testing the random walk properties as compared to other tests such as serial correlation tests, autoregressive and ARIMA models (Liu and He, 1991; Lo and MacKinlay, 1989). Following the process of Mobarek and Fiorante (2014), this study provides only detail discussion of various variance ratio tests. Therefore, runs test is quite commonly discussed in the existing literature.

\subsubsection{Variance Ratio Test}

Existing literature provides number of variance ratio tests to test the strict random walks (RWS) and relaxed martingale difference sequence (MDS) hypothesis. RWS hypothesis assumes that increments are homoscedastic, whereas MDS assumes that increments are caused by heteroscedasticity.

Lo and MacKinlay (1988) proposed single variance ratio test which suggests that increments are supposed to be serially uncorrelated if prices follow a random walk and variance in increments should increase linearly in the interval of sampling.

$p_{t}=p_{t-1}+\mu+\varepsilon_{t}, \quad \varepsilon_{t} \sim I I D \quad N\left(0, \sigma^{2}\right)$

The variance of $\left(p_{t}-p_{t-2}\right)$ should be twice the variance of $\left(p_{t}-p_{t-1}\right)$. In the same way the weekly time series should have five times more variance than the daily series (Karemera et al., 1999). Similarly if gold prices follow a random walk than the variance of $\left(p_{t}-p_{t-k}\right)$ should be $k$ times the variance of $\left(p_{t}-p_{t-1}\right)$ i.e $\operatorname{Var}\left(\mathrm{p}_{\mathrm{t}}-\mathrm{p}_{\mathrm{t}-\mathrm{k}}\right)=\mathrm{kVar}\left(\mathrm{p}_{\mathrm{t}}-\mathrm{p}_{\mathrm{t}-1}\right)$

Therefore, Lo and MacKinlay (1988) proposed variance ratio as follows:

$V R(k)=\frac{\left(\frac{1}{k}\right)\left(\operatorname{Var}\left(p_{t}-p_{t-k}\right)\right)}{\operatorname{Var}\left(\mathrm{p}_{\mathrm{t}}-\mathrm{p}_{\mathrm{t}-1}\right)}=\frac{\sigma^{2}(k)}{\sigma^{2}(1)}$

Where the null hypothesis for single variance ratio test is:

$$
H_{0}: \operatorname{VR}(k)=1
$$

Lo and MacKinlay (1988) also proposed two test statistics for the null hypothesis of random walk. First test statistic assumes homoscedastic increments, is used to test strict random walks (RWS) hypothesis and defined as follows:

$$
z_{1}(k)=\frac{V R(k)-1}{\phi(k)} \sim N(0,1)
$$




$$
\text { Where } \phi(k)=\sqrt{\frac{2(2 k-1)(k-1)}{3 k T}}
$$

The second test statistics that prefers to follow the assumption of heteroscedastic increments and is used to test the relaxed martingale difference sequence (MDS) hypothesis in this study as follows:

$$
z_{2}(k)=\frac{V R(k)-1}{\phi^{*}(k)} \sim N(0,1)
$$

Where $\phi^{*}(k)=\sqrt{\left[4 \sum_{t=1}^{k-1}\left(1-\frac{t}{k}\right) \delta_{t}\right]}$ and

$$
\delta_{t}=\frac{\sum_{i=t+1}^{T q}\left(p_{i}-p_{i-1}-\hat{\mathrm{u}}\right)^{2}\left(\left(p_{i-1}-p_{i-t-1}-\hat{\mathrm{u}}\right)^{2}\right.}{\left[\sum_{i=1}^{T q}\left(p_{i}-p_{i-1}-\hat{\mathrm{u}}\right)^{2}\right]^{2}}
$$

Luger (2003) suggested that non parametric tests provide robust results even the data are not normally distributed. Further, Wright (2000) modified parametric variance ratio test proposed by Lo and MacKinlay (1988) to a non-parametric variance ratio test. The main difference between the two tests is that Wright (2000) uses return ranks and signs instead of return differences used by Lo and MacKinlay (1988). Given T observations of asset returns i.e (y_1, ...... follows:

$$
\begin{aligned}
& R_{1}(k)=\left(\frac{(T K)^{-1} \sum_{t=k}^{T}\left(r_{1 t}+\cdots+r_{1 t-k+1}\right)^{2}}{T^{-1} \sum_{t=1}^{T} r_{1 t}^{2}}-1\right)\left(\frac{2(2 k-1)(k-1)}{3 k t}\right)^{-1 / 2} \\
& R_{2}(k)=\left(\frac{(T K)^{-1} \sum_{t=k}^{T}\left(r_{2 t}+\cdots+r_{2 t-k+1}\right)^{2}}{T^{-1} \sum_{t=1}^{T} r_{2 t}^{2}}-1\right)\left(\frac{2(2 k-1)(k-1)}{3 k t}\right)^{-1 / 2}
\end{aligned}
$$

Where

$$
r_{1 t}=\frac{r\left(y_{t}-\frac{T+1}{2}\right)}{\sqrt{\frac{(T-1)(T+1)}{12}}} \quad \text { and } \quad r_{2 t}=\phi^{-1}\left(\frac{r\left(y_{t}\right)}{T+1}\right)
$$

$r\left(y_{t}\right)$ denote rank of $y_{t}$ among $y_{1}, \ldots, y_{T}$ and $\phi^{-1}$ is the inverse of standard normal cumulative distribution function.

On the other hand, Wright (2000) proposed non parametric test based on the signs of returns, instead of ranks and defined $S_{1}$ and $S_{2}$ by the following equations: 


$$
\begin{aligned}
& S_{1}=\left(\frac{(T K)^{-1} \sum_{t=k}^{T}\left(s_{t}+\cdots+s_{t-k+1}\right)^{2}}{T^{-1} \sum_{t=1}^{T} s_{t}^{2}}-1\right) \times\left(\frac{2(2 k-1)(k-1)}{3 k t}\right)^{\frac{-1}{2}} \text { and } \\
& S_{2}=\left(\frac{(T K)^{-1} \sum_{t=k}^{T}\left(s_{t}(\bar{\mu})+\cdots+s_{t-k+1}(\bar{\mu})\right)^{2}}{T^{-1} \sum_{t=1}^{T} s_{t}(\bar{\mu})^{2}}-1\right) \times\left(\frac{2(2 k-1)(k-1)}{3 k t}\right)^{\frac{-1}{2}}
\end{aligned}
$$

Where $s_{t}=2 u\left(y_{t}, 0\right), s_{t}(\bar{\mu})=2 u\left(y_{t}, \bar{\mu}\right)$, and

$$
\mu\left(x_{t}, q\right)=\left\{\begin{aligned}
0.5 & \text { if } x_{t}>q \\
-0.5 & \text { otherwise }
\end{aligned}\right.
$$

By performing various simulations Wright (2000) proposed that under homoscedasticity conditions Rank tests such as $R_{1}$ and $R_{2}$ provide more robust results (RWS hypothesis), whereas signs tests such as $S_{1}$ and $S_{2}$ provide better results when there are heteroscedastic conditions. In This study, ranks tests are used to test the random walks (RWS) hypothesis, whereas signs tests to test the martingale difference sequence (MDS) hypothesis.

\section{Results Analysis and Discussion}

This section provides a discussion and analysis of runs test and various variance ratio tests to test the strict RWS and relaxed MDS hypothesis. Moreover, the results are further divided into three subgroups to test whether efficiency of gold markets in emerging countries such as in Russia, India and China has changed with the passage of time.

\subsection{Runs Test}

Table 2 provides results for runs test to test whether the successive price changes are invariant of time so they do not follow trend. In our case, runs test is used to test the RWS hypothesis for the whole period as well as for three sub periods. For whole the period, results indicate that gold market in Russia follows a random walk. In other words, Russian gold market is weak form efficient in terms of strict RWS. On other hand, two markets such as China and India are not weak form efficient as the null hypothesis is rejected for both the gold markets. Results for first sub period are consistent with whole period, since Russia is only found weak form efficient. Results for the second sub period are quite interesting since all markets are found weak form efficient, which indicates that emerging gold markets have evolved in terms of weak form efficiency as results reveal that all emerging countries show independent price changes. Results for third sub period are consistent with the results of first sub period and with whole sample. It indicates that Russia is found weak form efficient in terms of strict RWS, whereas China and India are found inefficient. 


\subsection{Variance Ratio Test}

Variance ratio test results for gold returns of the emerging markets are given in Table 3. Column 1 provides the number of days intervals that is lag $\mathrm{k}$, where $\mathrm{k}=2,5,10$ and

Table 02: Runs Test

\begin{tabular}{|c|c|c|c|c|c|c|c|}
\hline Market & $\begin{array}{l}\text { Test } \\
\text { Value }\end{array}$ & $\begin{array}{l}\text { Cases } \\
<\text { test } \\
\text { Value } \\
\end{array}$ & $\begin{array}{l}\text { Cases }>= \\
\text { test } \\
\text { Value }\end{array}$ & $\begin{array}{l}\text { Total } \\
\text { Cases }\end{array}$ & $\begin{array}{l}\text { Number } \\
\text { of runs }\end{array}$ & $\begin{array}{l}\text { Z- } \\
\text { Statistics }\end{array}$ & $\begin{array}{l}\mathbf{P} \\
\text { value }\end{array}$ \\
\hline \multicolumn{8}{|c|}{ Full Period : 1993:01-2016:10 } \\
\hline China & 0.00024 & 3261 & 2948 & 6209 & 3195 & 2.47 & $0.01 *$ \\
\hline India & 0.00035 & 3146 & 3063 & 6209 & 3217 & 2.89 & $0.00 *$ \\
\hline Russia & 0.00103 & 3120 & 3089 & 6209 & 3115 & 0.99 & 0.32 \\
\hline \multicolumn{8}{|c|}{ Sub period 1: 1993:01-1999:12 } \\
\hline China & 0.00014 & 1006 & 813 & 1819 & 952 & 2.22 & $0.02 *$ \\
\hline India & 0.00016 & 965 & 854 & 1819 & 952 & 2.05 & $0.04 *$ \\
\hline Russia & 0.00022 & 898 & 921 & 1819 & 848 & 0.52 & 0.60 \\
\hline \multicolumn{8}{|c|}{ Sub period 2: 2000:01-2005:12 } \\
\hline China & 0.00034 & 815 & 750 & 1565 & 785 & 0.16 & 0.87 \\
\hline India & 0.00038 & 773 & 792 & 1565 & 787 & 0.18 & 0.85 \\
\hline Russia & 0.00039 & 799 & 766 & 1565 & 803 & 1.05 & 0.29 \\
\hline \multicolumn{8}{|c|}{ Sub period 3: 2006:01-2016:10 } \\
\hline China & 0.00026 & 1440 & 1385 & 2825 & 1462 & 1.85 & $0.06 *$ \\
\hline India & 0.00046 & 1408 & 1417 & 2825 & 1486 & 2.74 & $0.00 *$ \\
\hline Russia & 0.00059 & 1423 & 1402 & 2825 & 1416 & 0.17 & 0.86 \\
\hline
\end{tabular}

Runs test is used to test the null hypothesis that is gold prices follow a random walks (RWS). *P value below 0.1 indicates that null hypothesis of weak form gold market efficiency is rejected at $10 \%$ significance level.

30 as proposed by Wright (2000). Column 2 and 3 show the results of the parametric test statistics proposed by Lo and MacKinlay (1988). $M_{1}$ is used under the assumption of homoscedasticity which in our case is used to test the random walks (RWS) hypothesis. On other hand, $M_{2}$ is used under the null hypothesis of heteroscedasticity which in our case is used to test the martingale difference sequence (MDS) hypothesis. The results in columns four through seven are based on non-parametric test statistics proposed by Wright (2000). In these columns, the ranks (R1 and R2) test the strict RWS hypothesis whereas signs (S1 and S2) test the relaxed MDS hypothesis.

\subsection{Variance Ratio Test}

Variance ratio test results for gold returns of the emerging markets are given in Table 
3. Column 1 provides the number of days intervals that is lag $\mathrm{k}$, where $\mathrm{k}=2,5,10$ and 30 as proposed by Wright (2000). Column 2 and 3 show the results of the parametric test statistics proposed by Lo and MacKinlay (1988). $M_{1}$ is used under the assumption of homoscedasticity which in our case is used to test the random walks (RWS) hypothesis. On other hand, $M_{2}$ is used under the null hypothesis of heteroscedasticity which in our case is used to test the martingale difference sequence (MDS) hypothesis. The results in columns four through seven are based on non-parametric test statistics proposed by Wright (2000). In these columns, the ranks (R1 and R2) test the strict RWS hypothesis whereas signs (S1 and S2) test the relaxed MDS hypothesis.

The results in Table 3 are given for the subsamples and the whole sample in the gold markets of the China, Russia, and India. The test statistics i.e M1 and M2 indicate that both RWS and MDS hypothesis cannot be rejected in case of China except when lag interval is 30 for M1. On other hand, the null hypothesis is rejected for all other test statistics i.e R1, R2, S1 and S2. These differences may be due to the reason that LM test statistics (M1 and M2) do not provide robust results under the presence of heteroscedasticity. For India and Russia null hypothesis is rejected for most of the lag intervals when M1 test statistics is used. Alternatively, the null hypothesis cannot be rejected for both India and Russia in case of M2. Finally, test statistics R1, R2, S1 and S2 reject both RWS and MDS hypotheses.

Overall, results for whole sample indicate that all three emerging gold markets are weak form inefficient, as both strict RWS and relaxed MDS hypothesis are rejected. These results are different from those of runs test, in case of Russia only, since runs test indicates that Russia is an efficient market.

For first sub period covering from January, 1993 to December, 1999, M1 and M2 test statistics indicate that China is an efficient market. On the contrary, Wright (2000) test statistics (R1, R2, S1 and S2) reject the null hypothesis of weak form market efficiency in case of China. For India, the null hypotheses (both RWS and MDS) are rejected against all the given test statistics for most of the lag intervals. It further indicates that India is weak form inefficient during first sub period. For Russia only M1 suggests weak form inefficiency of Russian gold markets, whereas all other test statistics do not reject null hypotheses of RWS and MDS except M2 at lag 2. These results, therefore, conclude that Russia was weak form efficient during first sub period. Discrepancies in M1 results may be due to the presence of heteroscedasticity in the data.

For sub period 2 ranging from January, 2000 to December, 2005, the null hypotheses are accepted against all the given test statistics except R1. In R1, the null hypothesis is rejected for India and China at lag 2 only. These results are consistent with runs test for sub period 2.

For sub period 3 commencing from January, 2006 to October, 2016, the test statistics i.e R1, R2, S1, and S2 suggest that Russia is weak form efficient. On other hand, China and India are not weak form efficient. However, test statistics proposed by Lo and MacKinlay (1988) give inconsistent results. Contrary to robust test statistics proposed by Wright (2000), M1 test statistics indicate that China is weak form efficient, whereas Russia is inefficient.

Sukkur IBA Journal of Management and Business - SIJMB | Volume 5 No. 1 January - June 2018 @ Sukkur IBA University 
Overall findings for period 2, except M1 and M2 test statistics results, suggest that for all three emerging markets, null hypotheses of weak form efficiency (both strict RWS and relaxed MDS) cannot be rejected for all test statistics including runs test; whereas for sub period one and sub period three, null hypothesis is rejected for China and India but not for Russia. These results therefore conclude that Russian gold market is found weak form efficient during all individual periods, whereas China and India became efficient during second sub period only. Moreover, results of two types of hypotheses are consistent with each other, that is, both types of hypotheses are accepted for Russia

Table 03: Variance ratio test results for China, India, and Russia

\begin{tabular}{lllllll}
\hline Period & M1 & M2 & R1 & R2 & S1 & S2
\end{tabular}

Full Period : 1993:01-2016:10

\begin{tabular}{|c|c|c|c|c|c|c|}
\hline \multicolumn{7}{|c|}{ China } \\
\hline 2 & -0.92 & -0.52 & $-2.46^{* * *}$ & $-2.02 * *$ & $-1.97^{* *}$ & $-3.45 * * *$ \\
\hline 5 & -1.61 & -0.90 & $-1.83^{*}$ & $-2.02 * *$ & $-1.87 *$ & $-3.06 * * *$ \\
\hline 10 & -1.27 & -0.72 & -0.37 & -1.56 & $-2.71 * * *$ & $-2.16 * *$ \\
\hline 30 & $-1.67 *$ & -0.98 & $-1.83^{*}$ & $-1.67 *$ & $-1.69 *$ & -1.53 \\
\hline \multicolumn{7}{|c|}{ India } \\
\hline 2 & $-1.69 *$ & -0.78 & $-1.77 *$ & $-2.87 * * *$ & $-1.95^{*}$ & $-3.85 * * *$ \\
\hline 5 & $-2.84 * * *$ & -1.47 & $-1.99 * *$ & $-2.67 * * *$ & $-1.66^{*}$ & $-3.19 * * *$ \\
\hline 10 & -1.14 & -0.82 & $-1.99 * *$ & -1.51 & $-1.73^{* *}$ & $-1.91 *$ \\
\hline 30 & -1.57 & -0.56 & $-1.70 *$ & -1.41 & -0.93 & -1.25 \\
\hline \multicolumn{7}{|c|}{ Russia } \\
\hline 2 & $-1.80 *$ & -0.24 & $-1.67 *$ & $-1.74 *$ & $-1.72 *$ & -1.38 \\
\hline 5 & $-2.86 * * *$ & -0.45 & $-1.71 *$ & $-1.96 * *$ & $-1.98 * *$ & $-2.01 * *$ \\
\hline 10 & $-3.17 * * *$ & -0.60 & $-1.69 *$ & -0.27 & $-1.92 *$ & $-1.92 * *$ \\
\hline 30 & -0.11 & -0.02 & -0.08 & 0.61 & -0.01 & $-1.68 *$ \\
\hline
\end{tabular}

Sub period 1: 1993:01-1999:12

\begin{tabular}{lllllll}
\hline China & & & & & & \\
2 & -1.47 & -0.68 & $-1.87 *$ & -0.41 & $-2.49 * *$ & $-2.53 * * *$ \\
5 & -0.87 & -0.48 & $-1.76^{*}$ & $-1.86^{*}$ & $-1.70^{*}$ & $-2.52 * * *$ \\
10 & 0.09 & 0.06 & $2.35^{* * *}$ & $-2.11^{* *}$ & $2.25 * *$ & $-2.07 *$ \\
30 & -0.18 & -0.15 & $-2.04 * *$ & $-2.02 * *$ & $-2.03 * *$ & -1.36 \\
India & & & & & & \\
2 & -1.07 & 0.53 & 0.38 & $-1.92^{*}$ & $-2.19 * *$ & $-2.15 * *$ \\
5 & $1.98^{* *}$ & $1.97 * *$ & 1.29 & $-1.99 * *$ & $-1.73 *$ & $-1.68 *$ \\
10 & $2.88^{* * *}$ & $2.64 * * *$ & $2.18 * *$ & $-2.56 * * *$ & $2.31 * *$ & $-1.98 * *$ \\
30 & 0.79 & $1.73 *$ & 0.51 & -0.89 & 0.36 & -1.04 \\
Russia & & & & & &
\end{tabular}




\begin{tabular}{lllllll}
\hline Period & M1 & M2 & R1 & R2 & S1 & S2 \\
\hline 2 & $8.92^{* * *}$ & $1.74^{*}$ & 1.49 & -0.58 & 0.72 & -0.77 \\
5 & $2.62^{* * *}$ & 0.46 & 0.98 & -0.24 & 0.18 & -1.23 \\
10 & $-3.95^{* * *}$ & -0.65 & -1.49 & -0.14 & -0.44 & -0.98 \\
30 & $-2.46^{* *}$ & -0.45 & -0.71 & 0.18 & -0.14 & -0.86 \\
\hline
\end{tabular}

Sub period 2: 2000:01-2005:12

\begin{tabular}{lllllll} 
China & & & & & & \\
2 & -1.00 & -0.61 & $-1.96^{* *}$ & -0.69 & -1.04 & -0.98 \\
5 & -0.24 & -0.16 & -0.48 & -0.13 & -0.29 & -0.35 \\
10 & -0.55 & -0.40 & -0.89 & -0.54 & -0.61 & -0.50 \\
30 & -1.27 & -1.04 & -1.50 & -0.95 & -1.24 & -0.61 \\
India & & & & & & \\
2 & -0.79 & -0.47 & $-1.90^{*}$ & -0.74 & -1.01 & -0.88 \\
5 & 0.33 & 0.22 & -0.24 & -0.15 & -0.15 & -0.37 \\
10 & 0.01 & 0.00 & -0.51 & -0.37 & -0.35 & 0.08 \\
30 & -0.86 & -0.68 & -1.22 & -0.83 & -1.00 & -0.07 \\
Russia & & & & & & \\
2 & -0.97 & -0.61 & -1.62 & -0.53 & -0.89 & -0.99 \\
5 & 0.11 & 0.07 & -0.09 & -0.03 & -0.05 & -0.58 \\
10 & -0.17 & -0.12 & -0.53 & -0.41 & -0.36 & -0.98 \\
30 & -0.89 & -0.73 & -1.08 & -1.00 & -0.89 & -1.56 \\
\hline & & & & & &
\end{tabular}

\section{Sub period 3: 2006:01-2016:10}

\section{China}

\begin{tabular}{lllllll}
2 & -0.48 & -0.36 & $-1.69^{*}$ & $-1.77^{*}$ & $-2.37 * *$ & $-2.35^{* *}$ \\
5 & -1.11 & -0.83 & $-1.73^{*}$ & $-1.74^{*}$ & $-2.43^{* * *}$ & $-2.26^{* *}$ \\
10 & -0.92 & -0.69 & -0.45 & -1.00 & -0.36 & -1.16 \\
30 & -1.16 & -0.89 & -1.16 & -1.09 & $-1.92^{*}$ & -0.73 \\
India & & & & & & \\
2 & -1.17 & -0.78 & $-1.74 *$ & $-2.54 * *$ & $-1.97 * *$ & $-3.33^{* * *}$ \\
5 & $-2.02^{* *}$ & -1.41 & $-1.97^{* *}$ & $-2.75^{* * *}$ & $-1.96^{* *}$ & $-3.15^{* * *}$ \\
10 & -0.85 & -0.61 & $-2.73^{* *}$ & -1.48 & $-2.55^{* * *}$ & $-2.12^{* *}$ \\
30 & -1.12 & -0.82 & -1.12 & -1.02 & $-1.85^{*}$ & -0.97 \\
Russia & & & & & & \\
2 & -1.37 & -0.26 & 0.31 & 0.20 & 0.12 & -0.69 \\
5 & $-2.03 * *$ & -0.46 & -0.35 & -0.68 & -0.16 & -1.56 \\
10 & $-2.15^{* *}$ & -0.59 & -0.56 & -0.04 & -0.28 & -1.34 \\
30 & 0.04 & 0.02 & 0.88 & 1.21 & 0.51 & -0.65 \\
\hline
\end{tabular}

*,** and $* * *$ indicate that null hypotheses are rejected at $10 \%, 5 \%$ and $1 \%$ level respectively. M1 and M2 test results are based on test statistics proposed by Lo and MacKinlay (1988) where M1 tests the strict random walks (RWS) hypothesis whereas M2 tests the relaxed martingale 
difference sequence (MDS) hypothesis. R1, R2, S1 and S2 tests are based on recent non parametric variance ratio tests proposed by Wright (2000) where R1 and R2 (ranks) test the strict random walks (RWS) hypothesis whereas S1 and S2 (signs) test the relaxed martingale difference sequence (MDS) hypothesis. M1, R1, and R2 test statistics are more robust when there are homoscedastic conditions whereas M2, S1, and S2 provide better results when there are heteroscedastic conditions.

during all individual periods whereas both are accepted for India and China during second sub period only. Results of test statistics proposed by Lo and MacKinlay (1988) (M1 and M2) are, however, not consistent with the findings of Wright (2000) and runs tests.

\section{Conclusion}

The objective of this study is twofold. First, to determine whether the emerging gold markets such as China, India and Russia are weak form efficient with the special focus on testing strict random walks (RWS) and relaxed martingale difference sequence (MDS) hypotheses. Moreover, whether the efficiency of these markets has evolved with the passage of time.

This study focuses on a number of biased-free statistical techniques such as runs test, Lo and MacKinlay (1988) parametric variance ratios tests (M1 and M2) and Wright (2000) modified non parametric variance ratio tests (R1, R2, S1, and S2) for testing two types of hypotheses. Moreover, this study further divides data into three sub periods for serving the second purpose of this study.

Findings based on runs test, and modified non parametric tests suggest that gold market in Russia is efficient throughout the sample period, whereas for India and China the findings are different for different periods. Both types of null hypotheses are rejected for India and China for period one (from January 1993 to December 1999) and period three (January 2006 to October 2016) but accepted for period two (January 2000 to December 2005), which employs that these two markets improved their efficiency during second period but that again deteriorated in the last period.

\section{References}

Basu, S., and Clouse, M. L. (1993). A comparative analysis of gold market efficiency using derivative market information. Resources Policy, 19(3), 217-224.

Batchelor, R., and Gulley, D. (1995). Jewellery demand and the price of gold. Resources Policy, 21(1), 37-42.

Baur, D. G. (2013). The autumn effect of gold. Research in International Business and Finance, 27(1), 1-11.

Baur, D. G., and Lucey, B. M. (2010). Is gold a hedge or a safe haven? An analysis of stocks, bonds and gold. Financial Review, 45(2), 217-229.

Baur, D. G., and McDermott, T. K. (2010). Is gold a safe haven? International evidence. Journal of Banking \& Finance, 34(8), 1886-1898.

Beckers, S. (1984). On the efficiency of the gold options market. Journal of Banking \& 
Finance, 8(3), 459-470.

Belaire-Franch, J., and Opong, K. K. (2010). Testing for random walk in euro exchange rates using the subsampling approach. Applied Economics Letters, 17(12), $1145-1151$.

Blose, L. E. (1996). Gold price risk and the returns on gold mutual funds. Journal of Economics and Business, 48(5), 499-513.

Blose, L. E., and Gondhalekar, V. (2013). Weekend gold returns in bull and bear markets. Accounting \& Finance, 53(3), 609-622.

Blose, L. E., and Shieh, J. C. (1995). The impact of gold price on the value of gold mining stock. Review of Financial Economics, 4(2), 125-139.

Caminschi, A., and Heaney, R. (2014). Fixing a leaky fixing: Short-term market reactions to the London PM gold price fixing. Journal of Futures Markets, 34(11), 1003-1039.

Chang, C.-L., Della Chang, J.-C., and Huang, Y.-W. (2013). Dynamic price integration in the global gold market. The North American Journal of Economics and Finance, 26, 227-235.

Davidson, S., Faff, R., and Hillier, D. (2003). Gold factor exposures in international asset pricing. Journal of International Financial Markets, Institutions and Money, 13(3), 271-289.

Dubey, P., Geanakoplos, J., and Shubik, M. (2003). Is gold an efficient store of value? Economic Theory, 21(4), 767-782.

Ewing, B. T., and Malik, F. (2013). Volatility transmission between gold and oil futures under structural breaks. International Review of Economics \& Finance, 25, 113-121.

Ho, Y.-K. (1985). A test of the incrementally efficient market hypothesis for the London gold market. Economics Letters, 19(1), 67-70.

Karemera, D., Ojah, K., and Cole, J. A. (1999). Random walks and market efficiency tests: Evidence from emerging equity markets. Review of Quantitative Finance and Accounting, 13(2), 171-188.

Lim, K. P., and Brooks, R. (2011). The evolution of stock market efficiency over time: a survey of the empirical literature. Journal of Economic Surveys, 25(1), 69108.

Liu, C. Y., and He, J. (1991). A Variance-Ratio Test of Random Walks in Foreign Exchange Rates. The Journal of Finance, 46(2), 773-785.

Lo, A. W., and MacKinlay, A. C. (1988). Stock market prices do not follow random walks: Evidence from a simple specification test. Review of financial studies, 1(1), 41-66.

Lo, A. W., and MacKinlay, A. C. (1989). The size and power of the variance ratio test in finite samples: A Monte Carlo investigation. Journal of Econometrics, 40(2), 203-238.

Luger, R. (2003). Exact non-parametric tests for a random walk with unknown drift under conditional heteroscedasticity. Journal of Econometrics, 115(2), 259276.

Mills, T. C. (2004). Statistical analysis of daily gold price data. Physica A: Statistical 
Mechanics and its Applications, 338(3), 559-566.

Mobarek, A., and Fiorante, A. (2014). The prospects of BRIC countries: Testing weakform market efficiency. Research in International Business and Finance, 30, 217-232.

Monroe, M. A., and Cohn, R. A. (1986). The relative efficiency of the gold and treasury bill futures markets. Journal of Futures Markets, 6(3), 477-493.

Narayan, P. K., Narayan, S., and Zheng, X. (2010). Gold and oil futures markets: Are markets efficient? Applied energy, 87(10), 3299-3303.

Parisi, A., Parisi, F., and Díaz, D. (2008). Forecasting gold price changes: Rolling and recursive neural network models. Journal of Multinational financial management, 18(5), 477-487.

Pierdzioch, C., Risse, M., and Rohloff, S. (2014). On the efficiency of the gold market: Results of a real-time forecasting approach. International Review of Financial Analysis, 32, 95-108.

Rockerbie, D. W. (1999). Gold prices and gold production: Evidence for South Africa. Resources Policy, 25(2), 69-76.

Shafiee, S., and Topal, E. (2010). An overview of global gold market and gold price forecasting. Resources Policy, 35(3), 178-189.

Sjaastad, L. A. (2008). The price of gold and the exchange rates: Once again. Resources Policy, 33(2), 118-124.

Sjaastad, L. A., and Scacciavillani, F. (1996). The price of gold and the exchange rate. Journal of international Money and Finance, 15(6), 879-897.

Solt, M. E., and Swanson, P. J. (1981). On the efficiency of the markets for gold and silver. Journal of Business, 453-478.

Tschoegl, A. E. (1978). Weak-form efficiency in the gold market.

Tschoegl, A. E. (1980). Efficiency in the gold market-a note. Journal of Banking \& Finance, 4(4), 371-379.

Tully, E., and Lucey, B. M. (2007). A power GARCH examination of the gold market. Research in International Business and Finance, 21(2), 316-325.

Wang, Y., Wei, Y., and Wu, C. (2011). Analysis of the efficiency and multifractality of gold markets based on multifractal detrended fluctuation analysis. Physica A: Statistical Mechanics and its Applications, 390(5), 817-827.

Wright, J. H. (2000). Alternative variance-ratio tests using ranks and signs. Journal of Business \& Economic Statistics, 18(1), 1-9.

Xu, X. E., and Fung, H.-G. (2005). Cross-market linkages between US and Japanese precious metals futures trading. Journal of International Financial Markets, Institutions and Money, 15(2), 107-124.

Yu, H.-C., and Shih, T.-L. (2011). Gold, crude oil and the weekend effect: a probability distribution approach. Investment Management and Financial Innovations, 8(2), 39-51.

Zhang, Y.-J., and Wei, Y.-M. (2010). The crude oil market and the gold market: Evidence for cointegration, causality and price discovery. Resources Policy, 35(3), 168-177. 